\title{
PENINGKATAN KEMAMPUAN TIMBANG TERIMA PASIEN MELALUI BUDAYA KOMUNIKASI SITUATION, BACKGROUND, ASSESSMENT, RECOMMENDATION (SBAR) DI RS DI BEKASI
}

\author{
Dian Anggraini ${ }^{1, *}$, Enie Novieastari ${ }^{2}$, Tuti Nuraini ${ }^{2}$ \\ ${ }^{1}$ Akademi Kesehatan Swakarsa, Jakarta, Indonesia \\ ${ }^{2}$ Fakultas Ilmu Keperawatan, Universitas Indonesia \\ *)E-mail: dian.anggraini@ukrida.ac.id
}

\begin{abstract}
ABSTRAK
Latar Belakang: Komunikasi tidak efektif dalam timbang terima dapat meningkatkan kejadian medication error, membahayakan pasien, memperpanjang proses perawatan, menurunkan kepuasan pasien, memperpanjang hari rawat pasien yang akan berdampak pada kurangnya mutu asuhan keperawatan yang diberikan pada pasien. Upaya meningkatkan mutu pelayanan salah satunya dengan menerapkan komunikasi Situation, Background, Assessment, Recommendation (SBAR). Komunikasi SBAR sudah mulai diterapkan pada kebijakan akreditasi rumah sakit, di beberapa rumah sakit masih ada yang belum menerapkan komunikasi SBAR. Tujuan: penelitian ini bertujuan mengidentifikasi perbedaan pengetahuan dan kemampuan perawat setelah pelatihan SBAR. Metode: pre-eksperiment dengan pre-post tanpa kelompok kontrol, sampel penelitian seluruh Perawat Primer dan Penanggung Jawab shift ( $\mathrm{n}=17$ ). Pengukuran pengetahuan dengan melakukan tes tertulis sebelum dan sesudah pelatihan, dan untuk data kemampuan perawat timbang terima dengan komunikasi SBAR dilakukan pengamatan timbang terima sebelum dan sesudah pelatihan dengan menggunakan lembar observasi. Analisis data dengan uji t berpasangan dan uji Wilcoxon. Hasil: ada perbedaan yang bermakna rerata pengetahuan sebelum dan sesudah pelatihan ( $p$-value $<0,001$ ), ada perbedaan yang bermakna rerata kemampuan perawat sebelum dan sesudah pelatihan komunikasi SBAR dalam timbang terima pasien antar shift (p-value $<0,001)$. Kesimpulan: komunikasi SBAR efektif untuk meningkatkan sosialisasi, motivasi, mentoring, supervisi, serta pengembangan pendidikan yang berkelanjutan.
\end{abstract}

Kata Kunci: Komunikasi, pengetahuan, SBAR, timbang terima

Improvement of the Handover Ability Through Situation, Background, Assessment, Recommendation (SBAR) Communication Culture in Hospital at Bekasi City

\section{ABSTRACT}

Background: Ineffective communication in the handover can increase the incidence of medication errors, endanger the patient, prolong the treatment process, reduce patient satisfaction, extend patient care days which will have an impact on the lack of quality nursing care provided to patients. To improve quality of service, one of them is to apply SBAR communication. SBAR communication is already implemented in accreditation policy at hospital. Meanwhile, there are some hospital not yet implement it. Objective: this study was to identify differences in nurses' knowledge and abilities after training. Methods: pre-experiment with pre-post without a control group, a sample of all Primary Nurse and Shift Guidance ( $n=17)$, Measurement of knowledge by conducting a written test before and after training, and measurement of the ability to handover nurses with SBAR communication conducted handover observations before and after training using observation sheets. Data analysis by paired t-test and Wilcoxon test. Results: there were significant differences in the mean of knowledge before and after training (p-value <0.001), there were significant differences in the mean ability of nurses before and after SBAR communication training in the handover of patients between shifts ( $p$-value $<0.001)$. Discussion: SBAR communication must become a culture, its implementation needs managerial support and nurse commitment. Conclusion: communication with SBAR could improve effectively socialization, motivation, mentoring, supervision, and continuing education development.

Keywords: Communication, knowledge, SBAR, handover 


\section{LATAR BELAKANG}

Kegiatan timbang terima merupakan kegiatan rutin yang dilakukan oleh perawat dalam menginformasikan kondisi terakhir pasien serta menjadi gerbang awal dalam mengelola asuhan keperawatan yang komprehensif dan berkesinambungan. Komunikasi tidak efektif dalam timbang terima pasien dapat meningkatkan kejadian medication error, membahayakan pasien, memperpanjang proses perawatan, menurunkan kepuasan pasien, memperpanjang hari rawat pasien, dan berakhir terhadap kurangnya mutu asuhan keperawatan yang diberikan kepada pasien (Malekzadeh, dkk., 2013).

Komunikasi dengan alur Situation, Background, Assesment, Recommendation (SBAR) merupakan alur atau metode komunikasi efektif, yaitu dapat meningkatkan 1) persepsi komunikasi dan efektivitas dalam kolaborasi, meningkatan penerimaan dan menurunkan kematian tidak terduga [Velji (2010) dalam Meester, dkk (2013)], 2) penurunan kesalahan pemberian obat, dari 30 kasus menjadi 18 kasus/1.000 pasien dan mengurangi angka sentinel event $89,9 / 1000$ menjadi 39,96/1000 pertahun (Haig, Sutton, \& Whittington, 2006); 3) kualitas pengobatan dan perawatan pasien dan keselamatan pasien (Kesten, 2011); Rachmah, Mustikasari, \& Gayatri, 2013); dan 4) kualitas mutu operan jaga (Goupil, 2009; Wahyuni, 2014).

Hasil wawancara dengan sepuluh perawat di rumah sakit yang akan diteliti, 90\% perawat belum terpapar informasi tentang komunikasi SBAR, pelaksanaan timbang terima belum menggunakan alur yang jelas walaupun standar prosedur operasional (SPO) timbang terima tersedia. Hasil observasi pelaksanaan timbang terima $75 \%$ informasi yang disampaikan adalah informasi medis, walaupun pendokumentasian perawatan ada dan tertulis. Belum tersosialisasi metode SBAR, dan belum maksimalnya pelaksanaan timbang terima di salah satu rumah sakit di Bekasi tersebut, maka peneliti tertarik untuk melakukan penelitian tentang pengaruh pelatihan komunikasi SBAR terhadap pengetahuan dan kemampuan perawat dalam timbang terima pasien antar shift di rumah sakit. Tujuan penelitian ini adalah mengidentifikasi pengetahuan dan kemampuan perawat antara sebelum dan sesudah pelatihan komunikasi SBAR dalam timbang terima pasien antar shift di rumah sakit.

\section{METODE}

Penelitian ini merupakan penelitian pre eksperiment dengan pre-post pelatihan tanpa menggunakan kelompok kontrol yang melibatkan 17 Perawat Primer (PP) dan Penanggung jawab (PJ) shift di ruang perawatan anak dan dewasa yang diambil dengan teknik total sampling. Analisis data demografi, dengan metode pengisian dengan check lists kolom pilihan yang tersedia yang terdiri dari data jenis kelamin, pendidikan, dan umur. Pengetahuan diukur dengan dengan dua puluh pertanyaan dari materi pelatihan. Lembar observasi pelaksanaan timbang terima yang sudah diterapkan oleh peneliti sebelumnya (Rachmah, Mustikasari, \& Gayatri, 2013; Djubaedah, dkk, 2013).

Sebelum dilakukan penelitian, peneliti meminta persetujuan responden dengan memberikan penjelasan mengenai kegiatan, tujuan, serta manfaat yang didapat, setelah itu responden mengisi formulir inform consent, sebagai bukti persetujuan menjadi responden. Pelatihan dilakukan selama dua hari oleh peneliti, hari pertama melatih observer yang terdiri dari kepala ruangan dan Clinical Instructure, hari kedua melatih peserta pelatihan yang terdiri dari PP dan PJ shift. Adapun teknik pelaksanaan pelatihan dibagi menjadi dua sesi. Sesi pertama memberikan materi komunikasi SBAR dalam timbang terima pasien antar shift selama 60 
menit dengan metode ceramah dan tanya jawab, dan sesi kedua melakukan role play timbang terima dengan komunikasi SBAR selama 90 menit.

Instrumen observasi timbang terima dengan alur SBAR pertama kali dipergunakan oleh Leonard dan diterapkan di Rumah Sakit Michael Colorado dalam upaya meningkatkan komunikasi yang efektif (Leonard, Graham, \& Bonacum, 2004). Dilanjutkan pengembangan dalam handoff form for nurse oleh Haig dan dimodifikasi oleh McMurray dkk., (2008). Pengembangan di Indonesia oleh Cahyono (2008) dalam Rachmah, Mustikasari, \& Gayatri (2013) dan Djubaedah, dkk (2013). Peneliti kemudian mengembangkan kembali sesuai dengan timbang terima keperawatan di Indonesia dan di Rumah Sakit yang akan diteliti yang terdiri dari dua belas pernyataan. Instrumen untuk pengetahuan dalam bentuk MCQ, dan lembar observasi menggunakan pilihan ya dan tidak.

Uji instrumen A (karakteristik responden), B (Tes materi pelatihan komunikasi SBAR), dan lembar observasi menggunakan uji keterbacaan untuk validitas instrumen yang dikonsultasikan dengan satu orang pakar keperawatan yang berkonsentrasi di bidang manajemen keperawatan. Uji reliabilitas untuk pengetahuan menggunakan alpha cronbach, adapun hasil $r$ hitung $=0,675$, dimana $r$ hitung lebih besar daripada $r$ tabel, secara statistik butir-butir pertanyaan reliabel.

Instrumen lembar observasi dilakukan uji cohen's kappa untuk mengukur persamaan persepsi. Hasilnya uji interrater reliability didapatkan nilai Kappa $>0,75$, sehingga hasil uji Kappa dari ke-empat observer tidak ada perbedaan persepsi dengan peneliti.

Pelaksanaan observasi komunikasi SBAR dalam timbang terima menggunakan bantuan dari observer. Observer selain ditentukan oleh peneliti, juga ditentukan oleh kepala ruangan. Observer terlebih dahulu dibekali kemampuan komunikasi SBAR dalam timbang terima, dan dilakukan uji persamaan persepsi sebelum melakukan pengamatan. Pelaksanaan pengamatan dilakukan setelah pendampingan pelaksanaan komunikasi SBAR dalam timbang terima. Intervensi diberikan selama dua hari, lalu dilaksanakan post test dengan menyesuaikan waktu dinas perawat.

\section{HASIL}

Hasil analisis dari karakteristik perawat berdasarkan jenis kelamin, tingkat pendidikan, umur, dan masa kerja dijelaskan dalam tabel 1 dan 2 sebagai berikut:

Tabel 1. Distribusi frekuensi PP dan PJ shift RSMS berdasarkan jenis kelamin dan tingkat pendidikan di RS di Bekasi $(n=17)$

\begin{tabular}{lcc}
\hline Variabel & $\mathrm{n}$ & Persentase (\%) \\
\hline Jenis kelamin & & \\
Laki-laki & 1 & 5,9 \\
Perempuan & 16 & 94,1 \\
Pendidikan & & \\
SPK & 2 & 11,8 \\
D III Keperawatan & 15 & 88,2 \\
Total & 17 & 100,0 \\
\hline
\end{tabular}

Mayoritas jenis kelamin PP dan PJ shift yaitu perempuan $(94,1 \%)$, dengan latar belakang pendidikan mayoritas D III Keperawatan. Hasil analisis variabel umur dan masa kerja terdistribusi normal $(p>0,05)$. Rerata umur 38,76 tahun dengan simpangan baku 5,985 (Tabel 2). Perbedaan pengetahuan PP dan PJ shift sebelum dan sesudah pelatihan secara rinci terlihat pada tabel 3. 
Tabel 2. Distribusi Distribusi PP dan PJ shift berdasarkan umur dan masa kerja di RS di Bekasi $(n=17)$

\begin{tabular}{lcc}
\hline Variabel & Rerata (s.b) & $\mathbf{9 5} \% \mathbf{~ C l}$ \\
\hline Umur & $38,76(5,985)$ & $35,69-41,84$ \\
Masa kerja & $17,59(6,285)$ & $14,36-20,82$ \\
\hline
\end{tabular}

Tabel 3. Perbedaan pengetahuan PP dan PJ Shift sebelum dan sesudah pelatihan komunikasi SBAR dalam timbang terima antar shift di RS di Bekasi $(n=17)$

\begin{tabular}{lllll}
\hline Pengetahuan & Rerata (s.b) & Selisih (s.b) & CI 95\% & p value \\
\hline Pre pelatihan & $37,94(11,327)$ & & & \\
Post pelatihan & $68,53(7,859)$ & $30,588(13,096)$ & $23,855-37,322$ & 0,001 \\
\hline
\end{tabular}

Tabel 3 adalah hasil dari uji $t$ berpasangan, diperoleh $p$ value $=0,001$ $(p<0,05)$ dengan selisih 30.588 (Cl 95\% -37.322 sampai -23.855). Karena nilai $p$ $<0,05$ dan confidence interval $(\mathrm{Cl})$ tidak melewati nol, secara statistik terdapat perbedaan yang bermakna rerata pengetahuan PP atau PJ shift sebelum dan sesudah pelatihan komunikasi SBAR dalam timbang terima pasien antar shift.

Hasil analisis kemampuan perawat PP atau PJ shift sebelum dan sesudah dapat dilihat pada tabel 4 sebagai berikut: komunikasi SBAR dalam timbang terima pasien antar shift.

\section{DISKUSI}

Berdasarkan hasil post pelatihan terkait pengetahuan PP dan PJ shift tentang komunikasi SBAR dalam timbang terima pasien antar shift, rerata pengetahuan yang didapat setelah pelatihan masih dalam kategori pengetahuan cukup. Hal tersebut berdasarkan pengkategorian pengetahuan. Menurut Notoatmodjo (2010), apabila responden dapat menjawab dengan

Tabel 4. Perbedaan kemampuan PP atau PJ Shift sebelum dan sesudah pelatihan komunikasi SBAR dalam timbang terima antar shift di RS di Bekasi $(n=17)$

\begin{tabular}{lll}
\hline Kemampuan & Median (minimum-maksimum) & p value \\
\hline Pre pelatihan & $66,0(33,0-83,0)$ & \multirow{2}{*}{0,001} \\
Post pelatihan & $83,0(58,0-100)$ & \\
\hline
\end{tabular}

Hasil penelitian menunjukkan bahwa perbedaan kemampuan perawat PP atau PJ shift antara sebelum dan sesudah pelatihan dengan $p$ value $<0,001$, secara statistik terdapat perbedaan kemampuan benar $56 \%$ s.d $75 \%$ dikategorikan cukup pengetahuannya. Hal tersebut menunjukkan bahwa walaupun secara statistik terjadi peningkatan rerata pengetahuan secara bermakna, namun peningkatan pengetahuan 
secara klinis kurang bermakna.

Pembentukan dan perubahan perilaku menurut teori pembelajaran sosial Bandura Social Learning Theory (BSLT) adalah bahwa perubahan perilaku yaitu adanya interaksi antara perilaku, kognitif, dan pengaruh lingkungan resiprokal atau bolakbalik (Bandura, 1978). Setiap tindakan atau perilaku individu secara psikodinamik digerakkan oleh motivasi, dan faktor lain yang mempengaruhi seperti kemampuan kognitif dan regulasi diri setiap individu. Perilaku individu digerakkan oleh motivasi dengan berusaha mempelajari respon dalam berperilaku dengan melihat pola respon yang ditujukan oleh orang lain.

Proses pembelajaran merupakan salah satu bagian pembentukan perilaku, dengan diberikan pembelajaran melalui pelatihan dapat meningkatkan pengetahuan dan keterampilan seseorang untuk menunjang penampilan kerja sesuai dengan tugasnya. Hal tersebut sependapat dengan Dessler (2006) dalam Marquis \& Huston (2010) yang menyatakan bahwa pelatihan adalah sebuah metode yang digunakan untuk mendapatkan keterampilan yang dibutuhkan untuk melakukan pekerjaannya. Hal ini sejalan dengan pernyataan As'ad (2004) bahwa pelatihan akan meningkatkan kemampuan pegawai, dan hasil penelitian Chaharsoughi, Ahrari, \& Alikhah (2014) dengan pelatihan menggunakan role play merupakan metode pendidikan yang efektif dalam teknik SBAR untuk perawat.

Berdasarkan hasil penelitian ini terjadi peningkatan kemampuan setelah pelatihan, namun nilai di bawah 60 , dan dari hasil uji Wilcoxon didapatkan satu orang PP atau PJ shift peserta pelatihan tidak terjadi peningkatan kemampuan timbang terima dengan komunikasi SBAR, sehingga perlu pembaharuan dan latihan yang berulang.

Hasil penelitian ini menunjukkan bahwa kemampuan perawat dalam timbang terima pasien antar shift mengalami perbedaan yang bermakna dengan menggunakan komunikasi SBAR, sesuai dengan hasil penelitian komunikasi SBAR dalam timbang terima sebelumnya bahwa metode SBAR efektif dilakukan (Rachmah, Mustikasari, \& Gayatri, 2013). Salah satu manfaatnya adalah meminimalkan kesalahan dan meningkatkan keselamatan pasien.

Hasil positif dari penelitian ini memerlukan komitmen dari perawat dan pihak rumah sakit, untuk menjadikan komunikasi SBAR sebagai metode komunikasi yang dilakukan saat timbang terima pasien, dibuatnya pedoman komunikasi efektif dengan metode SBAR, dan membuat SPO timbang terima dengan komunikasi SBAR sesuai dengan pedoman.

Penelitian selanjutnya dapat mempertimbangkan menerapkan desain penelitian yang lain, serta menggunakan metode komunikasi efektif yang lainnya. Penelitian ini tepat dilakukan karena sosialisasi komunikasi dengan metode SBAR belum menyeluruh, dan dapat meningkatkan kemampuan timbang terima pasien dengan optimal. Kekurangan dari penelitian ini adalah sampel penelitian minimal sehingga perlu ada pengembangan sampel pada penelitian selanjutnya.

\section{SIMPULAN}

Terdapat perbedaan yang bermakna pengetahuan dan kemampuan perawat dalam timbang terima pasien dengan komunikasi SBAR. Hasil penelitian ini dapat menjadi salah satu acuan untuk pedoman komunikasi efektif dengan komunikasi SBAR saat timbang terima pasien. Upaya meningkatkan pengetahuan dan kemampuan perawat yaitu dengan mengembangkan pendidikan berkelanjutan baik formal maupun non formal, motivasi, mentoring, dan supervisi yang berkelanjutan. Peneliti selanjutnya menerapkan desain 
penelitian eksperimen dengan kontrol, sampel yang lebih besar, jarak evaluasi yang optimal, serta menggali metode komunikasi efektif yang lainnya.

\section{UCAPAN TERIMA KASIH}

Terima kasih peneliti ucapkan kepada nara sumber ibu Dr. Rr. Tutik Hariyati, S.Kp., MARS., atas bantuan saran dan masukan untuk modul pelatihan dalam penelitian ini.

\section{DAFTAR PUSTAKA}

As'ad, M. (2004). Psikologi industri. Yogyakarta: Liberti.

Bandura, A. (1978). The self system in reciorocal determinism. American Psychologist, 33(4): 344-358. https://doi.org/10.1037/0003066X.33.4.344

Cahyono. (2008). Membangun budaya keselamatan pasien dalam praktek kedokteran. Yogyakarta: Kanisius.

Chaharsoughi, N.T., Ahrari, S., \& Alikhah, S. (2014). Comparison the effect of teaching of SBAR technique with roleplay and lecturing on communication skill of nurses. Journal of caring sciences, 3(2): 141-147.

Dessler, G. (2006). Manajemen sumber daya manusia. Edisi 10, Jilid 1. Jakarta: PT Indeks.

Djubaidah, S., Mustikasari., \& Gayatri, D. (2013). Pengaruh pelatihan komunikasi SBAR terhadap pengetahuan dan kepatuhan perawat pelaksana di Rumah Sakit Premier Jatinegara (Tesis). Program Magister IImu Keperawatan kekhususan kepemimpinan dan manajemen Keperawatan, Fakultas IImu Keperawatan. Depok, Indonesia.

Goupil, K. (2009). The effect of situation, background, assesment, recommendation (SBAR) education on the quality of student nurse handoff report. Proquest dissertation and thesis 73. Retrieved from http:// proquest.com

Haig, K. M., Sutton, S., \& Whittington, J. (2006). SBAR: A shared mental model for improving communication berween clinicans. Joint Commision Journal on Quality and Patient Safety, 32(3): 167-175.

Kesten, K.S. (2011). Role play using SBAR technique to improve observed communication skills in senior nursing student. Journal of Nursing Education, 50 (2), 79-87. doi: 10.3928/0148834-20101230-12.

Leonard, M., Graham, S., \& Bonacum, D. (2004). The human factor: the critical importance of effective team work and communication in providing safe care. Quality and Safety in Health Care, 13(2): i85-i90.

Malekzadeh, J., Mazluom S.R., Etezadi, T., \& Tasseri, A. (2013). A standardized shift handover protocol: improving nurses safe practice in intensive care unit. Journal of caring science 2013, 2(3): 177-185. Doi: 10.5681/ jcs.2013.022.

Marquis \& Huston (2010). Kepemimpinan dan manajemen keperawatan: teori dan aplikasi. Jakarta: EGC.

McMurray, P.A., Chsboyer, W., Wallis, M., \& Fetherston, C. (2010). Implementing bedside handover: strategies for change management. Journal of Clinical Nursing, 19(17-18): 25802589.

Meester, K.D., Verspuy, M., Monsieurs, K.G., \& Bogaert, P.V. (2013). SBAR improves nurse-physician communication and reduces unexpected death: a pre and post intervention study. j.resuscitation, 84 (9): 11921196. https://doi.org/10.1016/j.resuscitation.2013.03.016. 
Notoatmodjo, S. (2010). IImu Perilaku Kesehatan. Jakarta: Rineka Cipta.

Rachmah, Mustikasari, \& Gayatri (2013). Pengaruh komunikasi SBAR dalam timbang terima terhadap penerapan keselamatan pasien yang dipersepsikan oleh perawat pelaksanan di RSU Bunda Jakarta dan RSU Bunda Margonda. (Tesis). Program Magister IImu Keperawatan, Fakultas IImu Keperawatan, Universitas Indonesia. Depok, Indonesia.
Wahyuni, I. (2014). Efektifitas pelatihan komunikasi SBAR dalam meningkatkan mutu operan jaga (handover) di bangsal wardah RS PKU Muhammadiyah Yogyakarta Unit II. (Tesis). Universitas Muhammadiyah Yogyakarta. Yogyakarta, Indonesia. Retrieved from http://thesis.umy. ac.id/datapublik/t657.pdf. 